\title{
Relationships between strategic performance measures, strategic decision-making, and organizational performance: empirical evidence from Canadian public organizations
}

\section{Raili Pollanen, Ahmed Abdel-Maksoud, Said Elbanna \& Habib Mahama}

To cite this article: Raili Pollanen, Ahmed Abdel-Maksoud, Said Elbanna \& Habib Mahama (2017) Relationships between strategic performance measures, strategic decision-making, and organizational performance: empirical evidence from Canadian public organizations, Public Management Review, 19:5, 725-746, DOI: 10.1080/14719037.2016.1203013

To link to this article: https://doi.org/10.1080/14719037.2016.1203013

曲 Published online: 05 Jul 2016.

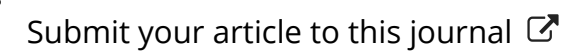

Llll Article views: 1999

Q View related articles $\sqsubset$

View Crossmark data ¿

Citing articles: 24 View citing articles 지 


\title{
Relationships between strategic performance measures, strategic decision-making, and organizational performance: empirical evidence from Canadian public organizations
}

\author{
Raili Pollanen ${ }^{\mathrm{a}}$, Ahmed Abdel-Maksoud ${ }^{\mathrm{b}}$, Said Elbanna $\mathbb{C}^{\mathrm{c}}$ and Habib Mahama ${ }^{\mathrm{d}}$

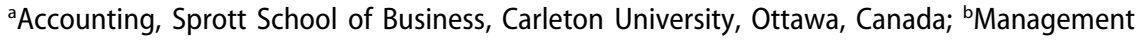 \\ Accounting, College of Business and Economics, United Arab Emirates University, Al-Ain, UAE; \\ 'Strategic Management, College of Business and Economics, Qatar University, Doha, Qatar; \\ ${ }^{\mathrm{d}}$ Accounting, College of Business and Economics, United Arab Emirates University, Al-Ain, UAE
}

\begin{abstract}
This study investigates the role of strategic performance measures (SPM) in strategic decision-making and their impact on organizational performance. Based on 143 online survey responses from senior administrators across Canadian public organizations, the study found that SPM of efficiency and effectiveness are positively associated with performance, as well as, the former with both strategy implementation and strategy assessment decisions. The study extends prior research by linking both SPM and their use in strategic decision-making to organizational performance.
\end{abstract}

KEYWORDS Organizational performance; strategic performance measures (SPM); strategy implementation; strategy assessment; Canadian public sector

\section{Introduction}

Strategic performance measures (SPM) are considered to be important for translating strategy into measurable objectives and, if appropriately designed and communicated, can facilitate strategy implementation, align management decisions and actions with strategic goals, and enhance organizational performance (Bisbe and Malagueno 2012; Franco-Santos, Lucianetti, and Bourne 2012; Micheli and Manzoni 2010). A few studies have investigated the extent to which SPM are deployed and their influence on organizational performance in public organizations (Micheli and Manzoni 2010). They have mainly focused on the deployment of SPM, rather than on strategic use of SPM and its longer-term performance effects, and implicitly assumed that, after SPM are deployed, they function in intended ways to generate organizational benefits. Furthermore, previous studies have not examined joint relationships between SPM deployment and practical activities of strategizing, although strategic planning processes are also associated with public-sector performance (Andrews et al. 2009; Jung and Lee 2013; Poister, Pasha, and Edwards 2013). This void has resulted in recent calls for further research on the use of SPM in strategic decision-making in the public 
sector (Hammerschmid, van de Walle, and Stimac 2013). This study contributes to filling this gap by investigating the use of SPM in strategic decision-making and its relationships with performance in public organizations.

Micheli and Manzoni (2010, 467) defined SPM systems by their four main attributes: "integration of long-term strategy and operational goals, presence of multi-perspective indicators, inclusion of cause-effect linkages, and presence of a sequence of goals-targets-action plans”. SPM in such systems can help organizations set and achieve strategic objectives, align individual behaviours and attitudes with strategic objectives, and, ultimately, enhance organizational performance. In particular, greater use of nonfinancial performance measures could contribute to more effective strategic alignment and organizational learning (Micheli and Manzoni 2010). The implications of these claims are substantial, tipping the relative importance and balance in SPM systems significantly from traditional financial measures towards nonfinancial measures.

In contemporary SPM systems, Franco-Santos, Lucianetti, and Bourne (2012) also emphasized the importance of nonfinancial performance measures linked to organizational strategy, along with core financial measures. In public organizations, nonfinancial performance measures become, in fact, relatively more important, given nonfinancial objectives and their subjective measurement (Pollanen 2005; Andrews, Boyne, and Walker 2006). For example, Liguori, Sicilia, and Steccolini (2012) found that both politicians and public managers considered nonfinancial performance measures more important and meaningful than financial measures. Although several studies have referred to financial and nonfinancial measures, categorizing measures as efficiency and effectiveness measures could be more relevant and useful, as they reflect outputs, productivity, and outcomes, not just whether measures are expressed in monetary terms. For example, Mitchell et al. (2013) argued that measurement of operating performance requires efficiency measures, which reflect input-output relationships, and measurement of strategic performance requires effectiveness measures, which reflect output-goal relationships. In this study, the classification of efficiency and effectiveness measures is adopted.

Strategic planning has often been conceptualized to entail two separate functions of strategic planning: strategy formulation and strategy implementation (Johnsen 2015; Mitchell et al. 2013). Although strategic management and strategic planning are used by some authors as synonyms (Elbanna 2013), the former is a more inclusive concept than the latter, because strategic management includes strategic planning along with implementation and evaluation processes (Bryson 2011; Poister 2005). More recently, authors have started looking towards the broader process of strategic management in the public sector instead of strategic planning itself (Poister and Streib 2005). For example, Mitchell et al. $(2013,19)$ considered strategic processes to involve: "(1) formulating a strategic plan, (2) implementing and monitoring the achievement of the strategic plan, and (3) reflecting, learning, and revising the strategic plan". Thus, strategic planning processes include control and feedback mechanisms that can indicate the achieved degree of coherence, that is, effectiveness, of strategic plans. More broadly, Poister (2010) surmised that "strategic planning processes need to facilitate understanding of the forces driving issues, explore options in terms of their feasibility and likely consequences, and stimulate candid discussions regarding the costs and risks associated with various alternatives". However, such complex relationships have not specifically been tested in the public sector. This study contributes to filling this gap by building on 
prior research to consider the role of SPM both in strategy implementation and strategy assessment decisions, along with their performance consequences.

Organizational performance in public organizations has widely been recognized as a multidimensional construct. For example, Boyne and Gould-Williams (2003) argued that financial measures alone are inadequate and inappropriate in capturing important multiple aspects of public-sector performance. They included indicators of service quality, cost, efficiency, and cost-effectiveness in their study and further reasoned that their relative importance can vary across stakeholder groups, complicating the assessment of impact of strategic planning on performance. In earlier research, Boyne (2002) had identified responsiveness (e.g., customer, citizen, and staff satisfaction), and democratic outcomes (e.g., accountability, probity, and participation) as potential outcomes. Subsequently, Andrews and van de Walle (2013), recognizing that most studies have focused on efficiency, incorporated multiple dimensions of public-service performance. They identified four dimensions of performance: efficiency, effectiveness, responsiveness, and equity, and found that strategic orientation exhibits a positive association with all four dimensions. In addition, Elbanna (2013) identified three main categories of strategic planning outcomes: strategic direction, fit with environment, and organizational performance. Organizational performance attributes included operational efficiency, effectiveness in achieving organizational objectives, and service quality. Therefore, the design of this study appropriately integrates multiple dimensions of organizational performance.

To conclude, this study contributes to the literature by focusing on use of performance information for strategic decision-making in public organizations, as well as, its impact on organizational performance. More specifically, it extends prior research in a comprehensive manner by: (1) considering SPM of both efficiency and effectiveness; (2) examining effects of SPM use on both strategy implementation and assessment decisions; (3) investigating both direct and indirect relationships between SPM, strategic decision-making, and performance; (4) incorporating multiple measures and analytical techniques; and (5) studying the less researched Canadian public organizations. In general, the findings reveal positive associations between SPM and organizational performance and, in particular, between SPM of efficiency and both strategy implementation and assessment.

The next section reviews relevant literature and develops the study hypotheses. The following two sections present the research method and the results, respectively. Finally, major findings and conclusions are discussed.

\section{Literature and hypotheses}

In this section, we review the relevant literature and introduce our research model. Building on prior empirical research in public-sector management, management accounting, and strategic and general management literature, we develop five main hypotheses underlying our research model, which is presented in Figure 1.

\section{SPM and organizational performance}

In a review of performance measurement literature, Franco-Santos, Lucianetti, and Bourne (2012) concluded that contemporary SPM can confer organizational benefits, such as behavioural modifications and improved organizational capabilities and performance. Similarly, Micheli and Manzoni (2010) argued that the design of SPM 


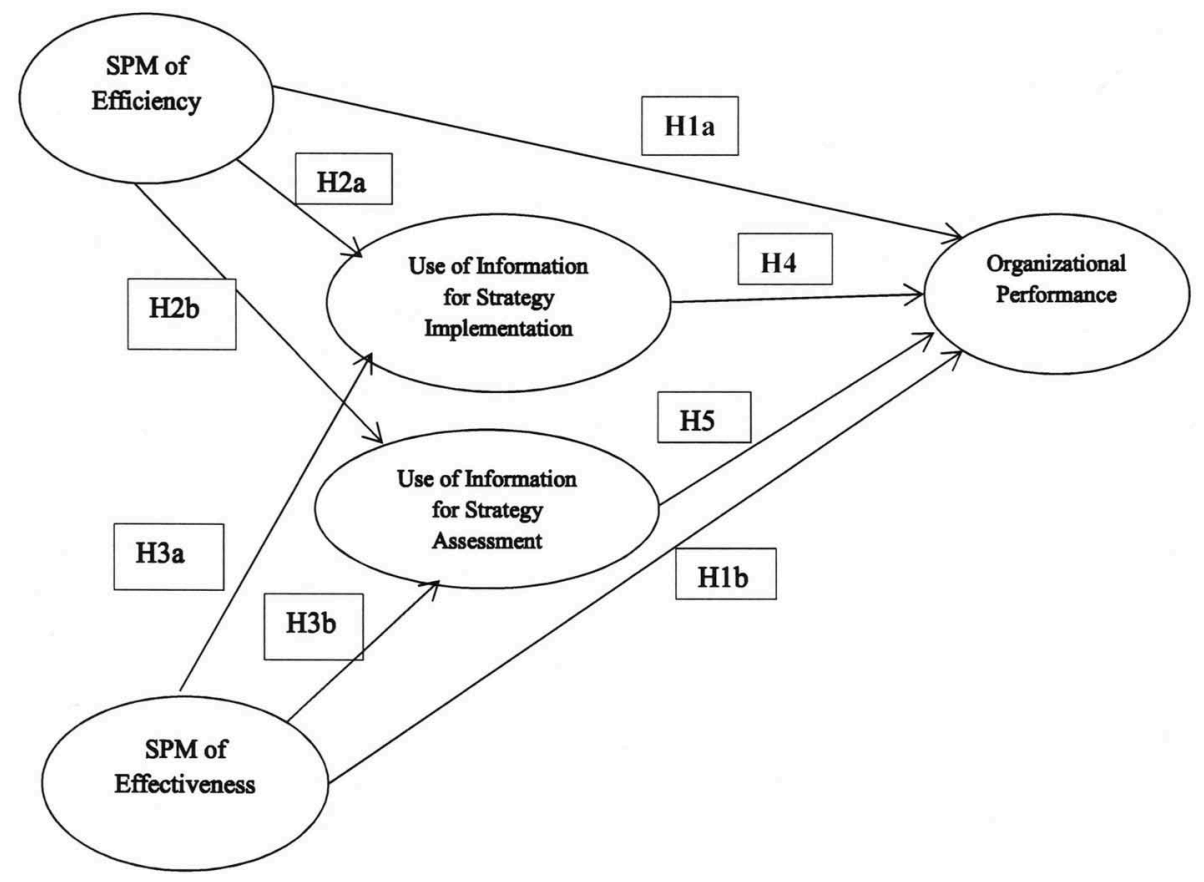

Figure 1. Conceptual model.

systems and their roles or uses are fundamental factors affecting organizational performance. On the other hand, Cavalluzzo and Ittner (2004) found that, although SPM were positively related to perceived results to date, they were unrelated to expected future results. Furthermore, any benefits were weak at best, if such measures were mandated instead of voluntarily implemented, signalling only symbolic use of mandated measures. In addition, SPM are multidimensional, requiring measures of both efficiency and effectiveness (Lebas and Euske 2002). Efficiency is concerned with achieving relatively short-term results with minimum resources and effectiveness with attaining longer-term organizational objectives (Boyne 2002). This dichotomy of measures is important for public organizations, in which direct measures of outcomes are typically not available (Pollanen 2005). For example, Mitchell et al. (2013) argued that it is important to differentiate between operational measures and SPM, and that strategic fit is achieved through strategic, not operational, performance, and it requires a long-term perspective. These examples demonstrate that measuring public-sector performance is faced with methodological and practical complexity.

Performance of operating units is often gauged by efficiency measures (i.e., inputoutput relationships), but alignment of operational and strategic performance requires effectiveness measures (i.e., output-goal relationships) (Mitchell et al. 2013). Andrews and van de Walle (2013) pointed out that efficiency has been overemphasized as compared to other performance dimensions, particularly effectiveness. This practice likely reflects internal efficiency measures being more objective and readily available in the short term than longer-term subjective effectiveness measures 
that require external data (Pollanen 2005). Not surprisingly, Hoque and Adams (2011) found that process efficiency measures were the most common measures and measures for employee learning and growth, which reflect effectiveness, were the least common. Similarly, Pollanen (2005) found that more efficiency measures than effectiveness measures were used, but that effectiveness measures were considered more desirable and their use was expected to increase. However, Andrews, Boyne, and Walker (2006) asserted that neither objective nor subjective measures are inherently superior and that both types of measures are needed.

Although an association between the use of SPM and organizational performance has been posited in several studies, such relationships can be difficult to validate empirically in public organizations. In the absence of internal accounting and market-based financial performance measures, measurement of performance in public organizations is complex and empirical studies scarce (Pollanen 2011). Cavalluzzo and Ittner (2004) argued that SPM are built on the assumption that they can improve efficiency and effectiveness by making public managers more accountable. Similarly, Umashev and Willet (2008) claimed that they were introduced in government organizations to increase accountability, effectiveness, and efficiency of resource use. Subsequently, Hoque and Adams (2011) found that SPM were perceived to enhance both programme efficiency and effectiveness. Furthermore, Pollanen (2011) concurred that SPM have commonly been adopted in response to widespread pressures on public organizations to improve the efficiency and effectiveness of their operations and services, as well as, accountability to regulators, public, and other stakeholders. However, McAdam, Hazlett, and Casey (2005), after finding increased focus on effectiveness, concluded that typical SPM are often oversimplified and still do not necessary address complex needs of diverse stakeholders. In recent years, advances have been made in developing more sophisticated outcome-oriented effectiveness measures, but it is clear from these examples that further efforts are warranted. There is still a notable research void in understanding relationships between the use of efficiency and effectiveness measures and organizational performance in public organizations. Therefore, this study incorporates SPM of both efficiency and effectiveness and their associations with organizational performance, leading to the following hypotheses:

$\boldsymbol{H}_{\mathbf{1 a}}$. There is a significant positive association between SPM of efficiency and organizational performance.

$\boldsymbol{H}_{\mathbf{1 b}}$. There is a significant positive association between SPM of effectiveness and organizational performance.

\section{SPM and strategic decision-making}

In order to investigate how benefits from SPM accrue to organizations, it is important to consider characteristics of SPM and roles they play in strategic processes, that is, for what purposes and how they are used. Franco-Santos, Lucianetti, and Bourne $(2012,99)$ concluded that SPM can 'facilitate the development, implementation, and review of business strategies by focusing people's 
decisions and actions on strategic goals and by encouraging a continuous dialogue about strategic endeavours'. Bhimani and Langfield-Smith (2007) found use of both financial and nonfinancial performance information in strategy development but more emphasis on financial information in strategy implementation. Subsequently, Gimbert, Bisbe, and Mendoza (2010) discovered that, although SPM did not influence the frequency of strategy formulation processes, they were associated with strategic agendas arising from these processes. Although SPM and strategy linkages have not been specifically studied in the public sector, the so-called planning school approach to strategic management, which involves programming, forecasting, and budgeting, has attempted to bridge public policy and strategy formulation and implementation, and it is widely used in public organizations (Johnsen 2015). Thus greater emphasis on nonfinancial information embedded in SPM could be beneficial for strategy formulation and implementation, as well as, strategy assessment, in public organizations.

More recently, attention has also been paid to strategy evaluation or assessment subsequent to its formulation and implementation in order to complete the strategic management cycle. Mitchell et al. (2013) aimed to develop a measurement tool for assessing the quality and strength of strategy and argued that strategy involves three functions: strategy formulation, strategy implementation and monitoring, and strategy revision based on reflection and learning. They also considered strategic fit to be the central purpose of strategic processes and stated that strategic performance assessment could be used to reveal the best possible fit between the organization's environment and its internal capabilities and resources. These processes are consistent with the learning school of thought (Johnsen 2015), which allows strategies to be refined in an emergent manner and used concurrently with formal strategic planning embedded in the planning school approach prevalent in public organizations. It is also consistent with feedback and emergent properties associated with complexity theory, which is particularly suitable for dealing with complex or so-called wicked problems common in many public organizations (Klijn 2008) ${ }^{1}$.

Several recent studies have examined determinants of performance information use in strategic decision-making in different contexts. In a literature review, Kroll (2015) identified important and promising drivers of performance information use, with the maturity of performance measurement systems being the first of six important drivers. Taylor (2011) found measurement systems and their perceived impact to be significantly associated with use of performance measures in decision-making in Australian state governments. Earlier, Taylor (2009) had found that performance measures were used more for meeting external reporting requirements than for internal decisionmaking, but that governments were more likely to use them for internal decisionmaking when they demonstrate validity, reliability, and legitimacy - characteristics that SPM information aims to satisfy. Cavalluzzo and Ittner (2004) also found top management commitment, decision-making authority, and training in performance measurement techniques to positively influence measurement system development and use in US government agencies. However, Hammerschmid, van de Walle, and Stimac (2013) discovered the use of performance information to vary among several European countries studied, different policy fields, and levels of government; and formal management practices, including strategic planning, to affect such use. Elbanna (2013) also found significant use of strategic management processes in general, and strategy 
evaluation in particular, along with related benefits in the public sector of the United Arab Emirates. These findings indicate that contextual factors can affect the use of performance information, particularly SPM, in strategic decision-making.

More specifically, considering important aspects of strategic decision-making separately, Abdel-Maksoud et al. (2015) investigated the use of financial and nonfinancial performance information for strategy implementation and strategy assessment decisions in Canadian public organizations and found that the importance of nonfinancial performance measures in general, and operational efficiency measures in particular, were significantly associated with the use of performance information for both strategy implementation and strategy assessment decisions. However, they did not specifically consider effectiveness measures or study impacts of measures and their use in decision-making on organizational performance. Furthermore, Elbanna, Andrews, and Pollanen (2015) considered it beneficial for future studies to incorporate determinants of strategy implementation success, including organizational systems and processes. This study extends the findings of these two studies, as well as, some others more generally (e.g., Taylor 2011; Cavalluzzo and Ittner 2004; Hammerschmid, van de Walle, and Stimac 2013) by investigating relationships between both efficiency and effectiveness measures and their use both for strategy implementation and assessment decisions, as expressed in the following hypotheses:

$\boldsymbol{H}_{2 a}$. There is a significant positive association between SPM of efficiency and the use of performance information for strategy implementation decisions.

$\boldsymbol{H}_{2 \boldsymbol{b}}$. There is a significant positive association between SPM of efficiency and the use of performance information for strategy assessment decisions.

$\boldsymbol{H}_{3 \boldsymbol{a}}$. There is a significant positive association between SPM of effectiveness and the use performance information for strategy implementation decisions.

$\boldsymbol{H}_{3 \boldsymbol{b}}$. There is a significant positive association between SPM of effectiveness and the use of performance information for strategy assessment decisions.

\section{Strategic decision-making and organizational performance}

The need to link strategy to performance and to evaluate such linkages by using SPM has been widely acknowledged. In general, Mitchell et al. (2013) argued that strategic planning can connect strategic objectives and related performance outcomes by monitoring and measuring the degree of their coherence or achievement. Similarly, Jung and Lee (2013) maintained that strategic planning and setting clear goals are critical functions of public managers, which are closely related to enhancement of organizational performance. They found that strategic planning capacity has positive impact on public-sector performance. Likewise, Poister and Streib (2005) claimed that strategic planning processes can link individual performance with strategic goals and objectives, report SPM to the public, evaluate the feasibility of proposed strategies, and track performance over time. Recently, Poister, Pasha, and Edwards (2013) cautiously concluded 
that formal strategic planning and performance measurement can contribute to improved public-service effectiveness, although their findings suggested that the impact of performance measurement may be stronger than that of strategic planning. These conclusions imply that both performance measurement and strategic planning functions are generally considered important in public organizations, but more precise mechanisms through which such benefits could accrue, as well as, their impacts are still not well understood.

Empirical research linking strategic planning with performance in public organizations is still rather scarce and results mixed (Poister, Pasha, and Edwards 2013). For example, Boyne and Gould-Williams (2003) provided early mixed evidence that some aspects of planning (e.g., favourable attitudes towards planning) were positively associated with organizational performance in Welsh local government; whereas, other aspects (e.g., number of quantitative performance targets) were negatively associated. Similarly, in a study of both public and private sectors of the United Arab Emirates, Elbanna (2012) reported that comprehensiveness of strategic decision-making positively influences organizational performance; whereas, extensiveness of strategic planning does not. In addition, Poister and Streib (2005) found in US local government that linking performance measures to strategy was less common than linking budgets to strategy. Moreover, Poister, Pasha, and Edwards (2013) reported that, while incrementalism in US local transit services was detrimental to performance, formal strategic planning or a combination of the two was associated with enhanced performance. With respect to strategy choices, Andrews et al. (2009) discovered that incrementalism and the lack of formal strategy can have negative implications for performance in Welsh local government; whereas, formal prospector and defender strategies are likely to enhance organizational performance. They concluded that both strategic processes and strategy content are important factors affecting performance of public organizations. In a subsequent study, Andrews et al. (2011) concluded that, in spite of only limited empirical evidence, strategy implementation is widely considered to be a critical element of strategy with a significant impact on publicsector performance.

Given some mixed results and a narrow local-government context of the abovementioned studies, this study further extends prior research by examining relationships between strategic decision-making and performance in various Canadian public organizations. In particular, it investigates empirically the performance consequences of the use of performance information in strategy implementation and assessment decisions, and also implicitly links strategy implementation success to organizational performance (Elbanna, Andrews, and Pollanen 2015). These arguments lead to the following hypotheses:

$\boldsymbol{H}_{4}$. There is a significant positive association between the use of performance information for strategy implementation decisions and organizational performance.

$\boldsymbol{H}_{5}$. There is a significant positive association between the use of performance information for strategy assessment decisions and organizational performance. 


\section{Research method}

\section{Sample selection and data collection}

The data were collected from Canadian public organizations, including all three levels of Canadian government organizations (federal, provincial, and municipal) through an online survey. Survey participants were identified from the Governments of Canada online database. The survey, in which a structured pretested questionnaire was used, was administered in 2012. Individually-addressed invitation emails that included links to the online survey and the cover letter were sent to 1,568 senior government officials with experience in performance measurement through an independent survey host company, followed by two rounds of reminder emails. A total of 249 individuals logged onto the survey site and 196 answered at least some questions, for a response rate of 12.5 percent. The analyses were based on the 143 substantially completed questionnaires. In rare cases of missing responses to a few individual items, analyses were based on the number of completed responses.

The response rate is consistent with that found in other recent online studies using similar procedures (Mirzaee 2014). However, in order to test for nonresponse bias, one-way ANOVA tests (Appendix 1) were performed to compare responses of early and late respondents on the number of employees reported - a proxy for organizational size (Wallace and Mellor 1988). As the results indicate no significant differences, the existence of nonrespondents does not likely pose a significant validity threat (Bryman and Cramer 2001).

\section{Measurement of variables}

Multi-item 5-point Likert-type scales were used to measure all constructs included in this study (Appendix 2). The scale items were adopted, or in some cases adapted, from prior studies and the final composite measures used were empirically validated.

\section{SPM}

An 11-item scale was adapted from previous public- and private-sector studies (Ittner, Larcker, and Randall 2003; Cavalluzzo and Ittner 2004; Abdel-Maksoud, Dugdale, and Luther 2005; Elbanna 2012). Respondents were asked to indicate: (a) to what extent their organizations had performance measures for specified performance areas; and (b) the importance of each performance criterion to the long-term success of their organization. Following Govindarajan and Fisher (1990) and Hyvonen (2007), the two scores (extent and importance) for each of the 11 items were multiplied. Originally, the 11 items included six items purportedly related to efficiency and five items related to effectiveness. We performed an explanatory factor analysis of these 11 items, and the results, in fact, revealed two factors ${ }^{2}$. The first factor was labelled, "SPM of efficiency", and the second factor, "SPM of effectiveness". SPM of efficiency and SPM of effectiveness are treated as two separate constructs in this study.

\section{Use of performance information for strategic decisions}

An 11-item scale was adopted from Cavalluzzo and Ittner (2004) and Ittner, Larcker, and Randall (2003) to gauge the extent to which organizations used performance measurement information for 11 purposes. An explanatory factor analysis of the 
items revealed two factors ${ }^{3}$. The first factor relates to "use of SPM information for strategy implementation decisions", and the second factor to "use of SPM information for strategy assessment decisions". Uses of SPM information for strategy implementation and assessment purposes are treated as two separate constructs in this study.

\section{Organizational performance}

Given the nature of public organizations under study and the survey method used, the perceived self-reported approach was used to measure organizational performance (Franco-Santos, Lucianetti, and Bourne 2012). An 11-item scale was developed based on previous public-sector studies to measure organizational performance (Cavalluzzo and Ittner 2004; Elbanna 2012). Respondents were asked to rate the performance of their organizations, as compared to similar organizations, at the current time, on the 11 items included.

We relied on self-reported measures for our strategy and performance variables for several reasons. First, it has been argued in prior studies that due to the confidentiality and sensitivity of strategy and performance data, managers are reluctant to provide direct (objective) measures for these variables in a survey (Dunk 1995; Venkatraman and Ramanujam 1986). Second, even when strategy and performance data are available, variances in accounting and reporting procedures across organizations make it difficult to accurately estimate direct (objective) measures (Mahama and Cheng 2013; Dess and Robinson Jr. 1984). Third, it has been argued in existing survey research that there is no empirical evidence to suggest that self-reported measures are worse than direct (objective) measures (Mahama and Cheng 2013; Dunk 1995; Abernethy and Stoelwinder 1991; Venkatraman and Ramanujam 1986). In fact, prior survey research has empirically established that self-reported measures and direct measures are strongly and significantly correlated (Dawes 1999; Hart and Banbury 1994; Pearce, Robbins, and Robinson 1987; Dess and Robinson Jr. 1984). It is important to recognize, however, that self-reported performance measures have been criticized in recent public performance measurement research. For example, Schachter (2010) argued for the use of measures obtained from citizens to complement measures from agency sources that may be subject to manipulation. In addition, Meier et al. $(2015,1098)$ found self-reported performance measures to be problematic, stating: "They are overly optimistic, correlate poorly with archival performance measures, lack any sophisticated judgement taking into account the resources and constraints of the organization, and can generate both false positive and false negative relationships in a non-systematic pattern compared to analyses based on archival data". Meier et al. advocated the use of archival data, if available, judgements by independent observers, or citizen surveys. Given such contradictory findings, we relied on self-reported measures for our strategy and performance variables but performed common method bias (variance) analysis, as reported in the subsequent discussion of the measurement model. The results suggest common method bias is not likely to be a serious concern in this study.

\section{Descriptive statistics and control variables}

Two control variables were incorporated into this study: the number of employees as a proxy for organizational size and the type of public sector. These variables have 
been advocated in public-sector performance literature (e.g., Hyvonen 2007). The vast majority (96 percent) of surveyed organizations are large, with an average of 2,443 full-time employees. Almost one half of the respondents represent provincial government organizations, about one quarter local government, and the remainder federal government and other governmental agencies. Statistical results indicate that the type of public sector is found to have significant associations with the use of SPM information for both strategy implementation $(t$-value $=1.795, p<0.05)$ and strategy assessment $(t$-value $=2.901, p<0.01)$ decisions; whereas, organizational size has no significant associations with any dependent variable.

\section{Results}

Structural equation modelling (SEM) with partial-least-squares (PLS) analysis was used to analyse the data. As PLS makes no data distribution assumptions, it can handle small sample sizes. The minimum sample size required for PLS is ten times the number of independent variables in the most complex regression in the model (Chin and Newsted 1999). As the most complex regression in our model has four independent variables, the minimum sample size is 40 . Thus, the sample size of 143 in this study is adequate. The $\mathrm{R}^{2}$-statistic was used to assess model stability and bootstrapping resampling to test for significance of factor loadings and path coefficients (Mahama and Cheng 2013). The analyses were conducted using SmartPLS 2.3 software.

\section{Measurement model}

The measurement model estimates relationships between scale measures and constructs they represent (Mahama and Cheng 2013). The PLS measurement model was used to assess individual item and composite reliabilities and also to evaluate convergent and discriminant validity. The results of the PLS model and descriptive statistics are summarized in Table 1.

Individual item reliability was assessed using the factor loadings of each item. The results show factor loadings greater than 0.70 for all items, except 0.64 for "social responsibility" performance, which are acceptable. Composite reliability measures for all constructs range from 0.856 to 0.961 , indicating good composite reliability. Convergent validity of the measurement model was assessed using each construct's average variance extracted (AVE) (Hair et al. 2010). The AVEs for all constructs are greater than 0.5 , ranging from 0.606 to 0.805 , and show adequate convergent validity. In addition, discriminant validity was assessed by checking that the square root of AVE for each construct is greater than its correlation with other constructs (Hair et al. 2010). For all constructs in our model, these relationships (Table 2) are true, which indicates adequate discriminant validity.

Harman's single-factor test was conducted to assess common method variance (Podsakoff et al. 2003). The results indicate a multifactor solution, posing no major validity threat. Furthermore, objectivity or the extent of agreement among respondents' judgments was also tested (Guilford 1954). The proportion of objectivity in each respondent's variance in any set of judgments depends on the extent to which his/her judgments are determined by common factors, known as communality. 
Table 1. Reliability and convergent validity and AVE.

\begin{tabular}{|c|c|c|c|c|c|c|}
\hline Latent variable & Min. & Max. & Mean & Standard deviation & Factor loadings & $t$-statistics \\
\hline \multicolumn{7}{|c|}{ SPM of efficiency (composite reliability $=0.902 ;$ AVE $=0.698$ ) } \\
\hline PM_Efficiency 1 & 1 & 5 & 2.86 & 1.37 & 0.838 & 30.380 \\
\hline PM_Efficiency 3 & 1 & 5 & 2.69 & 1.39 & 0.849 & 29.769 \\
\hline PM_Efficiency 4 & 1 & 5 & 2.70 & 1.36 & 0.805 & 18.631 \\
\hline PM_Efficiency 5 & 1 & 5 & 2.46 & 1.20 & 0.848 & 30.891 \\
\hline \multicolumn{7}{|c|}{ SPM of effectiveness (composite reliability $=0.856 ;$ AVE $=0.664$ ) } \\
\hline PM_Effectiveness 1 & 1 & 5 & 2.57 & 1.33 & 0.821 & 20.116 \\
\hline PM_Effectiveness 2 & 1 & 5 & 2.34 & 1.25 & 0.805 & 19.426 \\
\hline PM_Effectiveness 5 & 1 & 5 & 3.09 & 1.43 & 0.818 & 33.880 \\
\hline \multicolumn{7}{|c|}{ Use of SPM info. for strategy implementation decisions (composite reliability $=0.961$; AVE $=0.805$ ) } \\
\hline Info_Implement 1 & 1 & 5 & 2.98 & 1.236 & 0.923 & 73.003 \\
\hline Info_Implement 2 & 1 & 5 & 2.85 & 1.283 & 0.911 & 67.809 \\
\hline Info_Implement 3 & 1 & 5 & 2.97 & 1.278 & 0.917 & 62.413 \\
\hline Info_Implement 4 & 1 & 5 & 2.77 & 1.161 & 0.839 & 23.009 \\
\hline Info_Implement 5 & 1 & 5 & 3.01 & 1.244 & 0.881 & 40.696 \\
\hline Info_Implement 6 & 1 & 5 & 2.99 & 1.245 & 0.908 & 58.953 \\
\hline \multicolumn{7}{|c|}{ Use of SPM info. for strategy assessment decisions (composite reliability $=0.903 ;$ AVE $=0.650$ ) } \\
\hline Info_Assess 1 & 1 & 5 & 3.25 & 1.344 & 0.803 & 18.775 \\
\hline Info_Assess 2 & 1 & 5 & 2.66 & 1.340 & 0.789 & 20.242 \\
\hline Info_Assess 3 & 1 & 5 & 3.35 & 1.307 & 0.860 & 31.443 \\
\hline Info_Assess 4 & 1 & 5 & 3.33 & 1.373 & 0.851 & 30.825 \\
\hline Info_Assess 5 & 1 & 5 & 3.47 & 1.373 & 0.718 & 12.117 \\
\hline \multicolumn{7}{|c|}{ Organizational performance (composite reliability $=0.902 ;$ AVE $=0.606$ ) } \\
\hline OrgPerf 1 & 1 & 5 & 3.83 & .963 & 0.799 & 30.380 \\
\hline OrgPerf 3 & 1 & 5 & 3.89 & .906 & 0.802 & 29.769 \\
\hline OrgPerf 4 & 1 & 5 & 3.72 & .842 & 0.806 & 18.631 \\
\hline OrgPerf 5 & 1 & 5 & 3.47 & .933 & 0.805 & 30.892 \\
\hline OrgPerf 9 & 1 & 5 & 3.24 & .788 & 0.640 & 19.426 \\
\hline OrgPerf 11 & 1 & 5 & 3.71 & .977 & 0.802 & 33.880 \\
\hline
\end{tabular}

All item loadings on their respective constructs are statistically significant $(p<0.001$, one-tailed).

Table 2. Discriminant validity.

\begin{tabular}{|c|c|c|c|c|c|}
\hline & $\begin{array}{l}\text { SPM of } \\
\text { efficiency }\end{array}$ & $\begin{array}{c}\text { SPM of } \\
\text { effectiveness }\end{array}$ & $\begin{array}{c}\text { Use of SPM } \\
\text { information for } \\
\text { strategy } \\
\text { implementation } \\
\text { decisions }\end{array}$ & $\begin{array}{l}\text { Use of SPM } \\
\text { information for } \\
\text { strategy } \\
\text { assessment } \\
\text { decisions }\end{array}$ & $\begin{array}{l}\text { Organizational } \\
\text { performance }\end{array}$ \\
\hline SPM of efficiency & 0.836 & & & & \\
\hline SPM of effectiveness & 0.723 & 0.815 & & & \\
\hline $\begin{array}{l}\text { Use of SPM } \\
\text { information for } \\
\text { strategy } \\
\text { implementation } \\
\text { decisions }\end{array}$ & 0.557 & 0.429 & 0.897 & & \\
\hline $\begin{array}{l}\text { Use of SPM } \\
\text { information for } \\
\text { strategy } \\
\text { assessment } \\
\text { decisions }\end{array}$ & 0.467 & 0.427 & 0.672 & 0.806 & \\
\hline $\begin{array}{l}\text { Organizational } \\
\text { performance }\end{array}$ & 0.828 & 0.709 & 0.530 & 0.405 & 0.779 \\
\hline
\end{tabular}

Diagonal elements are square roots of AVE; off-diagonal elements are correlations between constructs. 
Factor analysis results revealed that 99 percent of communality values ranged from 0.90 to 1.00 , indicating a high degree of objectivity in the respondents' judgments.

\section{Structural model and hypotheses testing}

The PLS structural equation models were used for hypotheses testing. The main results are shown in Table 3, Panel A (additional analyses in Panels B and C), and summarized in Figure 2. $\mathrm{H}_{1 \mathrm{a}}$ predicted a significant positive association between SPM of efficiency and organizational performance. The analysis revealed a significant path coefficient $(0.622, p<0.0001)$ for this direct relationship. Similarly, as predicted in $\mathrm{H}_{1 \mathrm{~b}}$, a significant positive path coefficient $(0.221, p<0.0001)$ was found for the direct association between SPM of effectiveness and organizational performance. Hence, $\mathrm{H}_{1 \mathrm{a}}$ and $\mathrm{H}_{1 \mathrm{~b}}$ are corroborated.

$\mathrm{H}_{2 \mathrm{a}}$ predicted a significant positive association between SPM of efficiency and the use of performance information for strategy implementation decisions. The path coefficient is significant $(0.538, p<0.0001)$, indicating a direct positive association. Likewise, a significant positive path coefficient $(0.343, p<0.0001)$ was found between SPM of efficiency and the use of performance information for strategy assessment decisions, as predicted by $\mathrm{H}_{2 b}$. Hence, $\mathrm{H}_{2 \mathrm{a}}$ and $\mathrm{H}_{2 \mathrm{~b}}$ are also corroborated.

$\mathrm{H}_{3 a}$ predicted a significant positive association between SPM of effectiveness and the use performance information for strategy implementation decisions. The path

Table 3. PLS structural model results.

\begin{tabular}{|c|c|c|c|c|}
\hline \multirow[b]{2}{*}{ Latent variable } & \multicolumn{3}{|c|}{ Path coefficients ( $t$-statistics) } & \multirow[b]{2}{*}{$R^{2}$} \\
\hline & $\begin{array}{c}\text { Use of SPM information for } \\
\text { strategy implementation } \\
\text { decisions }\end{array}$ & $\begin{array}{c}\text { Use of SPM information } \\
\text { for strategy assessment } \\
\text { decisions }\end{array}$ & $\begin{array}{l}\text { Organizational } \\
\text { performance }\end{array}$ & \\
\hline \multicolumn{5}{|c|}{ Panel A: Path Coefficient, $t$-statistics (in parentheses), and $R^{2}$} \\
\hline SPM of efficiency & $0.538(5.587)^{* * * *}$ & $0.343(3.388)^{* * * *}$ & $0.622(9.371)^{* * * *}$ & - \\
\hline SPM of effectiveness & $0.024(0.235)$ & $0.164(1.446)$ & $0.221(3.551)^{* * *}$ & - \\
\hline $\begin{array}{l}\text { Use of SPM information } \\
\text { for strategy } \\
\text { implementation } \\
\text { decisions }\end{array}$ & - & - & $0.125(2.271)^{* * *}$ & 0.331 \\
\hline $\begin{array}{l}\text { Use of SPM information } \\
\text { for strategy assessment } \\
\text { decisions }\end{array}$ & - & - & $-0.046(0.756)$ & 0.304 \\
\hline $\begin{array}{l}\text { Organizational } \\
\text { performance }\end{array}$ & - & - & - & 0.727 \\
\hline Latent variable & Linkage & & $\begin{array}{l}\text { th to: Organization } \\
\text { performance }\end{array}$ & \\
\hline \multicolumn{5}{|c|}{ Panel B: Indirect effect and 95\% bootstrap confidence intervals (in parentheses) ${ }^{\mathrm{a}}$} \\
\hline $\begin{array}{lr}\text { SPM of } & \text { Use of SP } \\
\text { efficiency } & \text { decisio }\end{array}$ & $\begin{array}{l}\text { M information for strategy in } \\
\text { ns }\end{array}$ & nplementation & $\begin{array}{c}0.067 \\
(0.0014-0.0167)\end{array}$ & \\
\hline Latent variable & & Path to: Or & ganizational perfor & mance \\
\hline \multicolumn{5}{|c|}{ Panel C: Total effect ( $t$-statistics in parentheses) } \\
\hline SPM of efficiency & & & $\begin{array}{c}0.674 \\
(10.465)^{* * * *}\end{array}$ & \\
\hline
\end{tabular}

${ }^{*}=p<0.10 ;{ }^{* *}=p<0.05 ;{ }^{* * *}=p<0.01 ;{ }^{* * *}=p<0.0001$ (one-tailed); $N=143$.

${ }^{a}$ We used the bootstrap confidence interval estimation technique proposed in Hayes (2009) to determine the significance of indirect effects. 


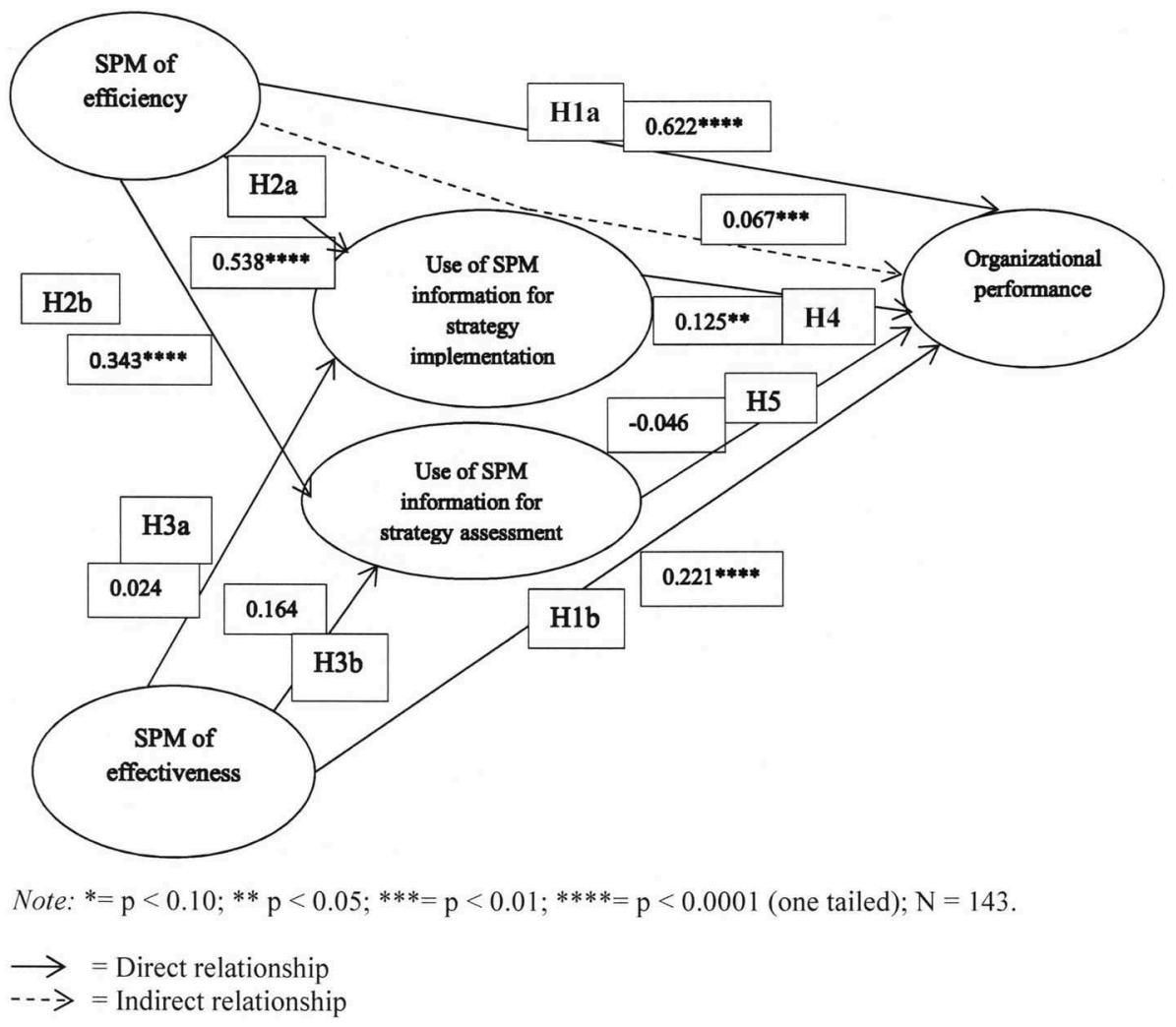

Figure 2. Results of PLS structural model.

coefficient, though in the predicted direction, is not significant $(0.024$, n.s.). Contrary to a predicted positive association between SPM of effectiveness and the use of performance information for strategy assessment decisions in $\mathrm{H}_{3 \mathrm{~b}}$, the path coefficient is also insignificant (0.164, n.s.). Hence, neither $\mathrm{H}_{3 \mathrm{a}}$ nor $\mathrm{H}_{3 \mathrm{~b}}$ is corroborated, indicating no significant direct relationships between SPM of effectiveness and the use of performance information for either strategy implementation or assessment decisions.

Furthermore, $\mathrm{H}_{4}$ predicted a significant positive association between the use of performance information for strategy implementation decisions and organizational performance. The path coefficient is significant $(0.125, p<0.01)$, supporting the expectation that the use of performance information for strategy implementation decisions can positively impact organizational performance. On the other hand, an insignificant negative path coefficient $(-0.046$, n.s.) was found, contrary to the positive association predicted between the use of performance information for strategy assessment decisions and organizational performance in $\mathrm{H}_{5}$. Therefore, $\mathrm{H}_{4}$ is corroborated but $\mathrm{H}_{5}$ is not.

Following these tests of direct effects, the indirect effect of SPM of efficiency on organizational performance through the use of performance information for strategy implementation decisions was also estimated. The bootstrap confidence interval 
estimation technique (Hayes 2009) was used to determine the significance of indirect effects. The results in Table 3 (Panel B) show that SPM of efficiency is significantly indirectly related to organizational performance, with a significant path coefficient (0.067, $p<0.01)$. This finding indicates that SPM of efficiency indirectly influences organizational performance through the use of performance information for strategy implementation decisions. Moreover, given that the results indicate both direct and indirect effects of SPM of efficiency on organizational performance, the total effect (direct plus indirect effects) was also estimated. The results (Table 3, Panel C) indicate that the total effect of SPM of efficiency on organizational performance is significant $(0.674, p<0.0001)$.

\section{Discussion and conclusions}

This study set out to examine the role of SPM in strategic decision-making and their impact on organizational performance. Consistent with prior studies (e.g., Cavalluzzo and Ittner 2004; Hoque and Adams 2011; Franco-Santos, Lucianetti, and Bourne 2012), the results corroborate the hypothesized positive relationships between SPM and organizational performance. These findings suggest that organizations can benefit from the appropriately implemented and used SPM. Furthermore, SPM use in strategic decision-making can amplify organizational performance, also supporting links between strategic processes and organizational performance found in prior studies (e.g., Andrews et al. 2009; Jung and Lee 2013; Poister, Pasha, and Edwards 2013). However, a significant relationship in this study was found only for strategy implementation but not for strategy assessment. A reason for the absence of significant results for strategy assessment could be that a longer time span is needed to capture the effects of strategy assessment decisions on organizational performance. These findings highlight the importance of developing appropriate types and mix of SPM for different purposes, even for different functions of strategic planning.

In addition, the lack of significant relationships between SPM of effectiveness and the use of that information both for strategy implementation and assessment decisions is noteworthy. In general, there has been a great deal of discussion about the importance of effectiveness measures, but it is difficult to measure effectiveness in the public sector due to its multidimensionality, long-term orientation, and subjectivity. Therefore, although managers recognize the importance of effectiveness measures, efficiency measures are still primarily used, because they are more objective and easily available regularly in the short term (Hoque and Adams 2011). However, processoriented efficiency measures are typically historical lagging measures, as opposed to more future-oriented or leading measures of effectiveness. Effectiveness measures can reflect longer-term, more ambiguous outcomes related, for example, to employee capabilities, longer-term client outcomes, and social and environmental responsibility. Due to diversity of public services and political short-term pressures affecting most public organizations, reliable and valid effectiveness measures are difficult to develop and use meaningfully. Furthermore, as effectiveness measures generally require external data, measurement of efficiency and effectiveness could be functions of different units or departments. For example, measurement of operating performance (efficiency) could be a responsibility of operating units; whereas, measurement of strategic performance (effectiveness) could be a function of the central institutional 
research office. In addition, there could be a significant time lag in obtaining and communicating effectiveness measures, decreasing their usefulness for strategic decision-making.

The findings of this study can contribute to both theory and practice. While the public sector has sought to deploy SPM, there has so far been little empirical evidence on the use of SPM information in decision-making by public managers (Cavalluzzo and Ittner 2004). Second, the study contributes to a better understanding of the extent to which public managers use performance information in general for strategic decisionmaking. Third, the study develops and validates multidimensional constructs of SPM, use of SPM information in strategic decision-making, and organizational performance. Finally, it provides empirical evidence in the Canadian context, which has been less studied in related literature. As such, the findings of the study can help public organizations establish a more informed foundation for strategic decision-making when dealing with financial crises and pursuing more sustainable stability and growth in the longer term (Osborne et al. 2014). Furthermore, the study contributes to an interdisciplinary perspective on public-sector performance management research (Van Helden, Johnsen, and Vakkuri 2008), by drawing on related studies in public-sector management, strategic management, general management, and management accounting literature.

Some limitations of the study should also be noted for future research considerations, such as typical caveats associated with survey research in general. Although multiple measures were used for each key construct, public-sector performance is known to be multidimensional and complex, and all important dimensions may not have been captured by the measures used. Also, as survey data collected from managers could raise self-reporting concerns, research design in future studies could benefit from data triangulation (Hall 2008). Although the study used a cross-sectional sample of Canadian public organizations, the results may not be generalizable to other jurisdictions or even to all Canadian public sectors due to the decentralized and diverse nature of these sectors. Furthermore, the study adopted a pragmatic managerial approach to performance measurement and strategic decision-making, leaving more critical political and institutional approaches mostly unaddressed. Future studies could build on these findings by replicating them in other contexts and providing sectoral and jurisdictional comparisons. Further research is also required to validate measures of public-sector performance, particularly measures of effectiveness, which could also include aspects of strategic fit and behavioural outcomes, such as perceived inequities and potential dysfunctional behaviours.

While Walker and his colleagues (e.g., Andrews et al. 2009, 2011; Walker 2013) showed the importance of linking strategy content/stances in public-sector organizations to other strategic factors such as strategy process, strategy implementation, environment, structure and organizational performance, neither our study nor their studies specifically considered the linkage between strategy content and the use of SPM. This gap in our study and related research presents an important avenue for future research.

\section{Notes}

1. In general, different strands of complexity theory deal with organizational change associated with complex interactions of various parts of dynamic organizational systems. They emphasize systems development nonlinearly, subject to various feedback mechanisms. These 
notions fit well with "modern ideas of complex decision-making, complex strategies and processes, and the emergent characteristics of processes and institutions in public administration theory" (Klijn 2008, 314).

2. Extraction method: principal component analysis based on Eigenvalues greater than 1; rotation method: Varimax with Kaiser normalization and maximum iteration for convergence of 25. The first factor, consisting of the first six items, was labelled, "SPM of efficiency" (Cronbach Alpha $=0.854$; factor loadings range 0.505-0.827; total variance explained = $31.0 \%)$. The second factor, consisting of the remaining five items was labelled, "SPM of effectiveness" (Cronbach Alpha $=0.799$; factor loadings range 0.463-0.686; total variance explained $=25.8 \%$ ).

3. The first six items fit together in one factor which relates to the "use of SPM information for strategy implementation decisions" (Cronbach Alpha $=0.952$; factor loading range $0.808-$ 0.884 ; total variance explained $=42.4 \%$ ). The remaining five items loaded onto the second factor which relates to the 'use of SPM information for strategy assessment decisions' (Cronbach Alpha $=0.864$; factor loadings range 0.629-0.830; total variance explained $=$ $32.1 \%)$.

\section{Acknowledgments}

Data collection for this study was carried out at Carleton University, Canada, in accordance with the university's approved research ethics protocol. Some preliminary results were presented at the 2015 Conference of Asia-Pacific Management Accounting Association, Bali, Indonesia, 26-29 October, 2015.

\section{Disclosure statement}

No potential conflict of interest related to this study exists for any of the four authors.

\section{Funding}

The authors are grateful for the 2-year research grant received from the National Research Foundation, United Arab Emirates (UAE-NRF\#: RSA-1108-00788), which enabled this research study to be carried out as part of a broader research programme.

\section{Notes on contributors}

Raili Pollanen, PhD, CPA (CMA) is an Associate Professor, Accounting, Sprott School of Business, Carleton University, Canada. Her research focuses on performance measurement, management, and governance in the public sector and it has been published in numerous academic journals, books, and international conference proceedings. She has also served on several professional committees, including a taskforce on Canadian public performance reporting.

Ahmed Abdel-Maksoud, $\mathrm{PhD}$, is an Associate Professor of Management Accounting, Accounting Department, College of Business and Economics, United Arab Emirates University, UAE. His research interests are in the fields of strategic performance measurement systems, eco-control systems, and neuroaccounting. He received research grants from various universities/research centers worldwide and published in numerous reputable journals, books and international conferences.

Saïd Elbanna is an Associate Professor at Qatar University. His research interests are in the areas of decision-making, strategic planning and internationalization of SMEs. He published in journals such as Strategic Management Journal, Long Range Planning, Tourism Management and Public Management Review. He received several research awards including the JMS Best Paper Award for 2007. 
Habib Mahama is an Associate Professor of Accounting at the United Arab Emirates University. He serves on the editorial boards of a number of international journals. His research interest is in the area of management accounting with specific focus on management accounting controls in interfirm relationships, management control of operational risk and behavioural management accounting. His research has been published in reputable international academic journals, books and conference proceedings.

\section{ORCID}

Said Elbanna (D) http://orcid.org/0000-0002-5891-8258

\section{References}

Abdel-Maksoud, A., D. Dugdale, and R. Luther. 2005. "Non-Financial Performance Measurement in Manufacturing Companies." The British Accounting Review 37 (3): 261-297. doi:10.1016/j. bar.2005.03.003.

Abdel-Maksoud, A., S. Elbanna, H. Mahama, and R. Pollanen. 2015. "The Use of Performance Information in Strategic Decision Making in Public Organizations." International Journal of Public Sector Management 28 (7): 528-549. doi:10.1108/IJPSM-06-2015-0114.

Abernethy, M. A., and J. U. Stoelwinder. 1991. "Budget Use, Task Uncertainty, System Goal Orientation and Subunit Performance: A test of the 'Fit' Hypothesis in Not-for-Profit Hospitals." Accounting, Organizations and Society 16 (2): 105-120. doi:10.1016/0361-3682(91)90008-3.

Andrews, R., G. A. Boyne, J. Law, and R. M. Walker. 2009. "Strategy Formulation, Strategy Content and Performance: An Empirical Analysis." Public Management Review 11 (1): 1-22. doi:10.1080/ 14719030802489989.

Andrews, R., G. A. Boyne, J. Law, and R. M. Walker. 2011. "Strategy Implementation and Public Service Performance." Administration \& Society 43 (6): 643-671. doi:10.1177/0095399711412730.

Andrews, R., G. A. Boyne, and R. M. Walker. 2006. "Subjective and Objective Measures of Organizational Performance: An Empirical Investigation." In Public Service Performance: Perspectives on Measurement and Management, edited by G. A. Boyne, K. J. Meier, L. J. O’Toole Jr., and R. M. Walker, 14-34. Cambridge: Cambridge University Press.

Andrews, R., and S. van de Walle. 2013. "New Public Management and Citizens' Perceptions of Local Service Efficiency, Responsiveness, Equity and Effectiveness." Public Management Review 15 (5): 762-783. doi:10.1080/14719037.2012.725757.

Bhimani, A., and K. Langfield-Smith. 2007. "Structure, Formality and the Importance of Financial and Non-Financial Information in Strategy Development and Implementation." Management Accounting Research 18 (1): 3-31. doi:10.1016/j.mar.2006.06.005.

Bisbe, J., and R. Malagueno. 2012. "Using Strategic Performance Measurement Systems for Strategy Formulation: Does it work in Dynamic Environments?” Management Accounting Research 23 (4): 296-311. doi:10.1016/j.mar.2012.05.002.

Boyne, G. A. 2002. "Concepts and Indicators of Local Authority Performance: An Evaluation of the Statutory Frameworks in England and Wales." Public Money \& Management 22 (2): 17-24. doi:10.1111/pmam.2002.22.issue-2.

Boyne, G. A., and J. Gould-Williams. 2003. "Planning and Performance in Public Organizations: An Empirical Analysis." Public Management Review 5 (1): 115-132. doi:10.1080/146166702200002889.

Bryman, A., and D. Cramer. 2001. Quantitative Data Analysis with SPSS Release 10 for Windows. New York, NY: Routledge.

Bryson, J. M. 2011. Strategic Planning for Public \& Nonprofit Organizations. 4th ed. San Francisco, CA: John Wiley.

Cavalluzzo, K., and C. Ittner. 2004. "Implementing Performance Measurement Innovations: Evidence from Government." Accounting, Organization and Society 29 (3-4): 243-267. doi:10.1016/S0361-3682(03)00013-8.

Chin, W. W., and P. R. Newsted. 1999. "Structural Equation Modeling Analysis with Small Samples Using Partial Least Squares.” In Statistical Strategies for Small Sample Research, edited by R. H. Hoyle, 307-341. Thousand Oaks, CA: Sage Publications. 
Dawes, J. 1999. "The Relationship between Subjective and Objective Company Performance Measures in Market Orientation Research: Further Empirical Evidence." Marketing Bulletin 10: 65-75.

Dess, G. G., and R. B. Robinson Jr. 1984. "Measuring Organizational Performance in the Absence of Objective Measures: The Case of the Privately-Held Firm and Conglomerate Business Unit." Strategic Management Journal 5 (3): 265-273. doi:10.1002/(ISSN)1097-0266.

Dunk, A. S. 1995. "The Joint Effects of Budgetary Slack and Task Uncertainty on Subunit Performance.” Accounting \& Finance 35 (2): 61-75. doi:10.1111/acfi.1995.35.issue-2.

Elbanna, S. 2012. "Slack, Planning, and Organizational Performance: Evidence from the Arab Middle East.” European Management Review 9 (2): 99-115. doi:10.1111/emre.2012.9.issue-2.

Elbanna, S. 2013. "Processes and Impacts of Strategic Management: Evidence from the Public Sector in the United Arab Emirates." International Journal of Public Administration 36 (6): 426-439. doi:10.1080/01900692.2013.772629.

Elbanna, S., R. Andrews, and R. Pollanen. 2015. "Strategic Planning and Implementation Success in Public Service Organizations: Evidence from Canada." Public Management Review. Advance online publication. doi:10.1080/14719037.2015.1051576.

Franco-Santos, M., L. Lucianetti, and M. Bourne. 2012. "Contemporary Performance Measurement Systems: A Review of their Consequences and a Framework for Research." Management Accounting Research 23 (2): 79-119. doi:10.1016/j.mar.2012.04.001.

Gimbert, X., J. Bisbe, and X. Mendoza. 2010. "The Role of Performance Measurement Systems in Strategy Formulation Processes.” Long Range Planning 43 (4): 477-497. doi:10.1016/j. lrp.2010.01.001.

Govindarajan, V., and J. Fisher. 1990. "Strategy, Control Systems, and Resource Sharing: Effects on Business-Unit Performance.” Academy of Management Journal 33 (2): 259-285. doi:10.2307/256325.

Guilford, J. 1954. Psychometric Methods. 2nd ed. London: McGraw-Hill.

Hair, J. F., W. C. Black, B. J. Babin, and R. E. Anderson. 2010. Multivariate Data Analysis: A Global Perspective. 7th ed. Upper Saddle River, NJ: Pearson.

Hall, M. 2008. "The Effect of Comprehensive Performance Measurement Systems on Role Clarity, Psychological Empowerment and Managerial Performance." Accounting, Organizations and Society 33 (2): 141-163. doi:10.1016/j.aos.2007.02.004.

Hammerschmid, G., S. van de Walle, and V. Stimac. 2013. "Internal and External Use of Performance Information in Public Organizations: Results from an International Survey." Public Money \& Management 33 (4): 261-268. doi:10.1080/09540962.2013.799803.

Hart, S., and C. Banbury. 1994. "How Strategy-Making Processes can Make a Difference." Strategic Management Journal 15: 251-269. doi:10.1002/(ISSN)1097-0266.

Hayes, A. F. 2009. "Beyond Baron and Kenny: Statistical Mediation Analysis in the New Millennium." Communication Monographs 76 (4): 408-420. doi:10.1080/03637750903310360.

Hoque, Z., and C. Adams. 2011. "The Rise and Use of Balanced Scorecard Measures in Australian Government Departments.” Financial Accountability \& Management 27 (3): 308-332. doi:10.1111/j.1468-0408.2011.00527.x.

Hyvonen, J. 2007. "Strategy, Performance Measurement Techniques and Information Technology of the Firm and their Links to Organizational Performance." Management Accounting Research 18 (3): 343-366. doi:10.1016/j.mar.2007.02.001.

Ittner, C. D., D. F. Larcker, and T. Randall. 2003. "Performance Implications of Strategic Performance Measurement in Financial Services Firms." Accounting, Organizations and Society 28 (7-8): 715-741. doi:10.1016/S0361-3682(03)00033-3.

Johnsen, A. 2015. "Strategic Management Thinking and Practice in the Public Sector: A Strategic Planning for All Seasons?” Financial Accountability \& Management 31 (3): 243-268. doi:10.1111/ faam.12056.

Jung, C. S., and G. Lee. 2013. "Goals, Strategic Planning, and Performance in Government Agencies.” Public Management Review 15 (6): 787-815. doi:10.1080/14719037.2012.677212.

Klijn, E.-H. 2008. "Complexity Theory and Public Administration: What's New? Key Concepts in Complexity Theory Compared to their Counterparts in Public Administration Research." Public Management Review 10 (3): 299-317. doi:10.1080/14719030802002675.

Kroll, A. 2015. "Drivers of Performance Information Use: Systematic Literature Review and Directions for Future Research.” Public Performance \& Management Review 38 (3): 459-486. doi:10.1080/15309576.2015.1006469. 
Lebas, M., and K. Euske. 2002. "A Conceptual and Operational Delineation of Performance." In Business Performance Measurement: Theory and Practice, edited by A. Neely, 65-79. Cambridge: Cambridge University Press.

Liguori, M., M. Sicilia, and I. Steccolini. 2012. "Some Like It Nonfinancial...Politicians' and Managers' Views on the Importance of Performance Information." Public Management Review 14 (7): 903-922. doi:10.1080/14719037.2011.650054.

Mahama, H., and M. M. Cheng. 2013. "The Effect of Managers' Enabling Perceptions on Costing System Use, Psychological Empowerment, and Task Performance." Behavioral Research in Accounting 25 (1): 89-114. doi:10.2308/bria-50333.

McAdam, R., S.-A. Hazlett, and C. Casey. 2005. "Performance Management in the UK Public Sector: Addressing Multiple Stakeholder Complexity." International Journal of Public Sector Management 18 (3): 256-273. doi:10.1108/09513550510591542.

Meier, K. J., S. C. Winter, L. J. O'Toole Jr., N. Favero, and S. C. Andersen. 2015. "The Validity of Subjective Performance Measures: School Principals in Texas and Denmark." Public Administration 93 (4): 1084-1101. doi:10.1111/padm.12180.

Micheli, P., and J.-F. Manzoni. 2010. "Strategic Performance Measurement Systems: Benefits, Limitations and Paradoxes." Long Range Planning 43 (4): 465-476. doi:10.1016/j.lrp.2009.12.004.

Mirzaee, A. 2014. "Response Rate Statistics for Online Surveys: What Numbers Should You be Aiming for." FluidSurveys. http://fluidsurveys.com/university/response-rate-statistics-online-sur veys-aiming/

Mitchell, F., L. B. Nielsen, H. Nørreklit, and L. Nørreklit. 2013. "Scoring Strategic Performance: A Pragmatic Constructivist Approach to Strategic Performance Measurement." Journal of Management \& Governance 17 (1): 5-34. doi:10.1007/s10997-012-9216-7.

Osborne, S. P., Z. Radnor, I. Vidal, and T. Kinder. 2014. "A Sustainable Business Model for Public Service Organizations? Editorial Essay.” Public Management Review 16 (2): 165-172. doi:10.1080/ 14719037.2013.872435.

Pearce, J. A., D. K. Robbins, and R. B. Robinson Jr. 1987. "The Impact of Grand Strategy and Planning Formality on Financial Performance." Strategic Management Journal 8: 125-134. doi:10.1002/(ISSN)1097-0266.

Podsakoff, P., S. MacKenzie, J. Lee, and N. Podsakoff. 2003. "Common Method Biases in Behavioral Research: A Critical Review of the Literature and Recommended Remedies." Journal of Applied Psychology 88 (5): 879-903. doi:10.1037/0021-9010.88.5.879.

Poister, T. H. 2005. "Strategic Planning and Management in State Departments of Transportation." International Journal of Public Administration 28 (13): 1035-1056. doi:10.1080/ 01900690500290611.

Poister, T. H. 2010. "The Future of Strategic Planning in the Public Sector: Linking Strategic Management and Performance." Public Administration Review December (Special Issue) 246254. doi:10.1111/j.1540-6210.2010.02284.x.

Poister, T. H., O. Q. Pasha, and L. H. Edwards. 2013. "Does Performance Management Lead to Better Outcomes? Evidence from the U.S. Public Transit Industry." Public Administration Review 73 (4): 625-636. doi:10.1111/puar.2013.73.issue-4.

Poister, T. H., and G. Streib. 2005. "Elements of Strategic Planning and Management in Municipal Government: Status after Two Decades." Public Administration Review 65 (1): 45-56. doi:10.1111/ puar.2005.65.issue-1.

Pollanen, R. 2005. "Performance Measurement in Municipalities: Empirical Evidence in Canadian Context." International Journal of Public Sector Management 18 (5): 4-24. doi:10.1108/ 09513550510576125.

Pollanen, R. 2011. "Relative Performance Benchmarking of Local Governments: Case of Ontario Municipalities.” International Journal of Business and Public Administration 8 (1): 19-33.

Schachter, H. L. 2010. "Objective and Subjective Performance Measures: A Note on Terminology." Administration \& Society 42 (5): 550-567. doi:10.1177/0095399710378080.

Taylor, J. 2009. "Strengthening the Link between Performance Measurement and Decision Making." Public Administration 87 (4): 853-871. doi:10.1111/padm.2009.87.issue-4.

Taylor, J. 2011. "Factors Influencing the Use of Performance Information for Decision Making in Australian State Agencies." Public Administration 89 (4): 1316-1334. doi:10.1111/padm.2011.89. issue-4. 
Umashev, C., and R. Willet. 2008. "Challenges to Implementing Strategic Performance Measurement Systems in Multi-Objective Organizations: The Case of a Large Local Government Authority." Abacus 44 (4): 377-398. doi:10.1111/abac.2008.44.issue-4.

Van Helden, G. J., A. Johnsen, and J. Vakkuri. 2008. "Distinctive Research Patterns on Public Sector Performance Measurement of Public Administration and Accounting Disciplines." Public Management Review 10 (5): 641-651. doi:10.1080/14719030802264366.

Venkatraman, N., and V. Ramanujam. 1986. "Measurement of Business Performance in Strategy Research: A Comparison of Approaches." Academy of Management Review 11 (4): 801-814.

Walker, R. M. 2013. "Strategic Management and Performance in Public Organizations: Findings from the Miles and Snow Framework." Public Administration Review 73 (5): 675-685. doi:10.1111/puar.2013.73.issue-5.

Wallace, R. S., and C. J. Mellor. 1988. "Non-Response Bias in Mail Accounting Surveys: A Pedagogical Note.” The British Accounting Review 20 (2): 131-149. doi:10.1016/0890-8389(88)90036-4.

\section{Appendix 1}

\section{Comparison of early and late responses (one-way ANOVA)}

\begin{tabular}{lcc} 
& \multicolumn{2}{c}{ ANOVA } \\
\cline { 2 - 3 } Group & $\mathrm{F}$ & Sig \\
\hline 1 & 0.341 & 0.560 \\
2 & 2.019 & 0.158 \\
3 & 2.139 & 0.146 \\
4 & 0.066 & 0.797 \\
5 & 0.006 & 0.941 \\
6 & 0.027 & 0.870 \\
\hline
\end{tabular}

Comparison of accumulated responses within a period with the remaining accumulated responses, as follows:

Group 1: Responses within the last two weeks (4\%) with remaining responses (96\%);

Group 2: Responses within last three weeks (22\%) with remaining responses (78\%);

Group 3: Responses within last four weeks (23\%) with remaining responses (77\%);

Group 4: Responses within last five weeks (34\%) with remaining responses (66\%);

Group 5: Responses within last six weeks (51\%) with remaining responses (49\%); and

Group 6: Responses within last seven weeks (56\%) with remaining responses (44\%).

\section{Appendix 2 \\ Constructs and measures}

\section{SPM}

\begin{tabular}{ll}
\hline & $\begin{array}{c}\text { (a) To what extent does your organization have performance measures for the } \\
\text { following performance areas? 1 }\end{array}$ \\
Iminimal extent) to 5 (great extent) & (b) How important is each criterion to the long-term success of your organization? \\
Item code & \multicolumn{1}{c}{1 (minimally important) to 5 (very important) } \\
\hline PM Efficiency 1 & Efficient use of allocated budget \\
PM Efficiency 2 & Quantity of products or services provided \\
PM Efficiency 3 & Quality of products or services provided \\
PM Efficiency 4 & Customer satisfaction \\
PM Efficiency 5 & Operating efficiency \\
PM Efficiency 6 & Product/service development or innovation \\
PM Effectiveness 1 & Employee satisfaction \\
PM Effectiveness 2 & Employee capabilities \\
PM Effectiveness 3 & Social responsibilities \\
PM Effectiveness 4 & Environmental performance \\
PM Effectiveness 5 & Accountability for results to external parties \\
\hline
\end{tabular}




\section{Use of SPM information for strategy implementation and assessment decisions}

\begin{tabular}{|c|c|}
\hline Item code & $\begin{array}{l}\text { To what extent does your organization use performance measurement information for the } \\
\text { following purposes? } 1 \text { (minimal extent) to } 5 \text { (great extent) }\end{array}$ \\
\hline Info_Implement 1 & Setting programme priorities \\
\hline Info_Implement 2 & Allocating resources \\
\hline Info_Implement 3 & Adopting new programme approaches or changing work processes \\
\hline Info_Implement 4 & Coordinating programme efforts with other internal or external organizations \\
\hline Info_Implement 5 & Refining programme performance measures \\
\hline Info_Implement 6 & Setting new or revising existing strategic objectives \\
\hline Info_Assessment 1 & Setting individual job expectations for employees \\
\hline Info_Assessment 2 & Rewarding employees \\
\hline Info_Assessment 3 & Reporting to higher level of management \\
\hline Info_Assessment 4 & Reporting to governing board or body \\
\hline Info_Assessment 5 & Reporting to higher level of government or regulatory agency \\
\hline
\end{tabular}

\section{Organizational performance}

Please rate the performance of your organization, compared to similar organizations at the Item code current time, on each of the following criteria. 1 (very poor) to 5 (very good)

$\begin{array}{ll}\text { OrgPerf } 1 & \text { Efficient use of allocated budget } \\ \text { OrgPerf 2 } & \text { Quantity of products or services provided } \\ \text { OrgPerf } 3 & \text { Quality of products or services provided } \\ \text { OrgPerf } 4 & \text { Customer satisfaction } \\ \text { OrgPerf } 5 & \text { Operating efficiency } \\ \text { OrgPerf } 6 & \text { Product/service development or innovation } \\ \text { OrgPerf } 7 & \text { Employee satisfaction } \\ \text { OrgPerf } 8 & \text { Employee capabilities } \\ \text { OrgPerf } 9 & \text { Social responsibilities } \\ \text { OrgPerf } 10 & \text { Environmental performance } \\ \text { OrgPerf } 11 & \text { Accountability for results to external parties }\end{array}$

